\title{
MODELLING THE SENSITIVITY OF UNDERGROUND SPACE STABILITY TO THE IN SITU STRESS UNCERTAINTIES: CASE STUDY AT THE BUKOV UNDERGROUND RESEARCH FACILITY PHASE II (ROŽNÁ MINE, CZECHIA)
}

\author{
Libin GONG (巩利斌) ${ }^{1,2) ~ *, ~ K a m i l ~ S O U C E K ~}{ }^{1)}$, Petr WACLAWIK ${ }^{1)}$, Martin VAVRO ${ }^{1)}$, \\ Lubomir STAS ${ }^{1)}$, Jan NEMCIK ${ }^{2)}$ and Sahendra RAM ${ }^{3)}$ \\ 1) Department of Geomechanics and Mining Research, Institute of Geonics of the Czech Academy of Sciences, \\ Ostrava, 70800, Czechia \\ $\left.{ }^{2}\right)$ School of Civil, Mining and Environmental Engineering, Faculty of Engineering and Information Sciences, University of Wollongong, \\ Wollongong, 2500, Australia \\ 3) Department of Mining Engineering, National Institute of Technology, Rourkela, Odisha, India
}

*Corresponding author's e-mail: libin.gong@ugn.cas.cz

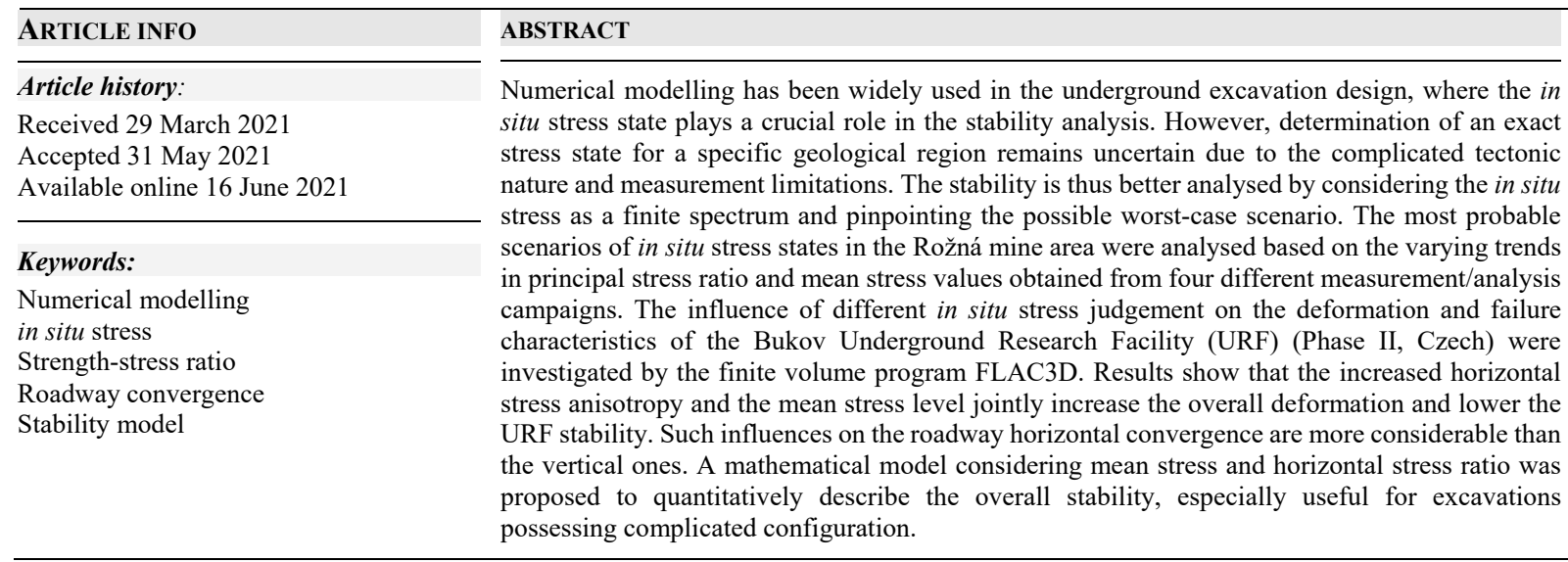

\section{INTRODUCTION}

Deep geological repositories (DGRs) have been constructed all over the world for disposal of high-level radioactive waste and spent nuclear fuel, which has been widely accepted to be the safest way of long-term isolation and containment of such waste materials (Apted and Ahn, 2017; Feiveson et al., 2011). A large number of underground research facilities (URFs) have also been built in many countries to investigate the geological, geomechanical and environmental issues of such DGRs and to study their isolation ability and performance (Apted, 2019; Bukovská et al., 2019; Delay et al., 2014; Laverov et al., 2016; NEA-OECD, 2013; Wang et al., 2018). The first part of the Bukov URF, which contains $475 \mathrm{~m}$ of galleries in total, was successfully constructed between 2013 and 2017 in the Rožná Mine area (hereinafter referred to as the Bukov URF - Phase I) (Souček et al., 2017). Recently, it is planned to expand the existing capacity of URF by excavating new galleries (hereinafter referred to as the Bukov URF Phase II) with a total length of $860 \mathrm{~m}$ in geotechnical conditions.

The Bukov URF - Phase II is designed to be located at a depth of $550 \mathrm{~m}$ below ground level in crystalline complexes of the Bohemian Massif. The stated depth is the same as already existing Bukov URF - Phase I and corresponds with the proposed disposal depth of the final locality for the national DGR. Five groups of laboratory roadways/chambers and two ventilation channels are to be excavated along a main transport roadway maintained from the original uranium mining area. Before the construction commencement of the Bukov URF - Phase II, it is essential to evaluate the feasibility and stability of the designed roadway and chamber layouts. The complex 3-dimensional (3D) geometry configuration of the caverns, in situ stress states and the existence of foliation in the metamorphic rock mass are all important parameters dominating the URF stability. Due to such characteristics of complexity, stability analysis or the estimation of the factor of safety (FoS) for the cavern groups is better to be conducted through numerical simulation (Peng et al., 2019).

When numerically analysing the excavation stability, the in situ stress state is one of the most important parameters dominating the FoS (Barton et al., 1974; Brady and Brown, 2007; Singh and Goel, 2011). The regional in situ stress should be determined by combining and integrating existing available 
geological data, field stress measurement results and numerical modelling (Stephansson and Zang, 2012). So far, all kinds of methods have been established to measure the in situ stress, including hydraulic fracturing, hydraulic tests on pre-existing fractures, sleeve fracturing, borehole relief, and borehole breakout etc. (Amadei and Stephansson, 1997; Haimson and Cornet, 2003; Hudson et al., 2003; Sjöberg et al., 2003; Zang and Stephansson, 2010). However, the inaccuracy and imprecision during in situ stress measurement is inevitable (Sjöberg et al., 2003). Even though large numbers of in situ measurement have been conducted, the results could still lie within a certain range. Complicated crustal movement and structure formation in the history make the engineering judgement for one exact in situ stress state in the region even more difficult and impractical. How to determine the input values of the far-field stresses for the related numerical model is a considerable question yet barely considered during engineering consultancy and assessment. Different combinations of three principal stress components in the model may lead to significantly different results (Saeidi et al., 2021). The worst-case scenario should be identified to avoid overestimation of the safety factor of the excavation. Hence, sensibility analysis using the upper and lower limits of the field-measured in situ stress data is necessary.

This paper investigated the influence of different in situ stress states on the stability of a planned Bukov URF - Phase II located $550 \mathrm{~m}$ deep underground in the Czech Republic, within the scope of real measurement data obtained from different locations in the excavation region. The Itasca program Fast Lagrangian Analysis of Continua in 3 Dimensions (FLAC3D) (Itasca Consulting Group, 2012) is employed in this paper to analyse the stability of the URF, which has been widely adopted to numerically model and analyse the stability of engineering projects ranging from underground excavations to rock slopes on the ground surface (Corkum et al., 2018; Napa-García et al., 2019; Renani and Martin, 2020). The results highlighted the significance and necessity of careful treatment of the field-measured in situ stress values for the application in numerical modelling, and proposed novel methods to quantitatively describe the overall stability of similar underground excavations with complicated configuration.

\section{GEOLOGICAL BACKGROUND}

\subsection{LITHOLOGY}

The region of interest is formed by a highly metamorphosed volcano-sedimentary rock sequence at the north-eastern edge of the Strážek Moldanubicum Unit of the Bohemian Massif (Bukovská et al., 2019; Kř́ibek and Hájek, 2005; Ptáček et al., 2013; Souček et al., 2017; Vavro et al., 2015). The dominant rock types are paragneisses, migmatites and amphibolites with minor intercalation of calc-silicate rocks, marbles, granulites, granites/pegmatites, and peridotites. Both basic lithologies, i.e. original metapelites (paragneisses) and metabasites (amphibolites) are affected by different degree of migmatization and are usually connected by gradual mutual transitions. The subjected area of Bukov URF - Phase II is formed mainly (in about $90 \%$ of the area) by: (1) medium- to coarse-grained migmatites, and (2) fine- to medium-grained, slightlyto medium-migmatized biotite- to biotite-amphibole paragneisses with transition to biotite amphibolites (Fig. 2.1). These two lithology types are very close to each other in terms of geomechanical properties. For simplicity, we consider the rock masses in this region as quasi-homogeneous and consist of one general rock type with similar mechanical properties.

\subsection{GEOLOGICAL STRUCTURES}

As shown in Figure 2.1, the whole rock sequence in the area of interest is trending relatively monotonously in the directions NW-SE to NNW-SSE. The dominant system of metamorphic fabric is represented by metamorphic foliations, in general gently to moderately dipping towards SW.

The first-order tectonic structure (zone R-1) occurs in the immediate vicinity of the survey area. This fault zone has a direction of N-S to NNW-SSE and a general dip of $45-55^{\circ}$ to $\mathrm{W}$, representing a cataclastic to mylonitized zone with a thickness of about 5-15 m and a strike length of up to $15 \mathrm{~km}$ (Kř́bek and Hájek, 2005). In terms of mineralization, zone $\mathrm{R}-1$ is one of the two main ore-bearing structures of the Rožná uranium deposit. The second-order tectonic structures (e.g. zone R-17) are spatially and probably also genetically associated with zone $\mathrm{R}-1$.

\subsection{EVALUATION OF GEOMECHANICAL PROPERTIES OF ROCK MASSES}

The input mechanical and deformation properties of the Bukov URF - Phase II rock mass, needed for the numerical model, were determined based on available geological survey and laboratory testing data. More specifically, three types of rocks tested within previous projects (Bukovská et al., 2020; Souček et al., 2018) which are petrographically very similar to Bukov URF - Phase II rocks (Fig. 2.1) were chosen. Laboratory testing was conducted in three different directions to their metamorphic foliation planes. The aim was to capture the anisotropy of mechanical and deformation properties, which is in the rock mass in question very well-known (Bukovská et al., 2020; Bukovská et al., 2019; Souček et al., 2018; Vavro et al., 2015). Testing results are summarised in Table 2.1.

The ubiquitous joint model is an appropriate failure criterion for the rock mass with clear anisotropy, considering the role of weak planes of specific orientation. However, it is difficult to determine the material properties compared with the Hoek-Brown criterion where systematic guidelines for the properties assignment have been established. As the ubiquitous joint model does not consider the 


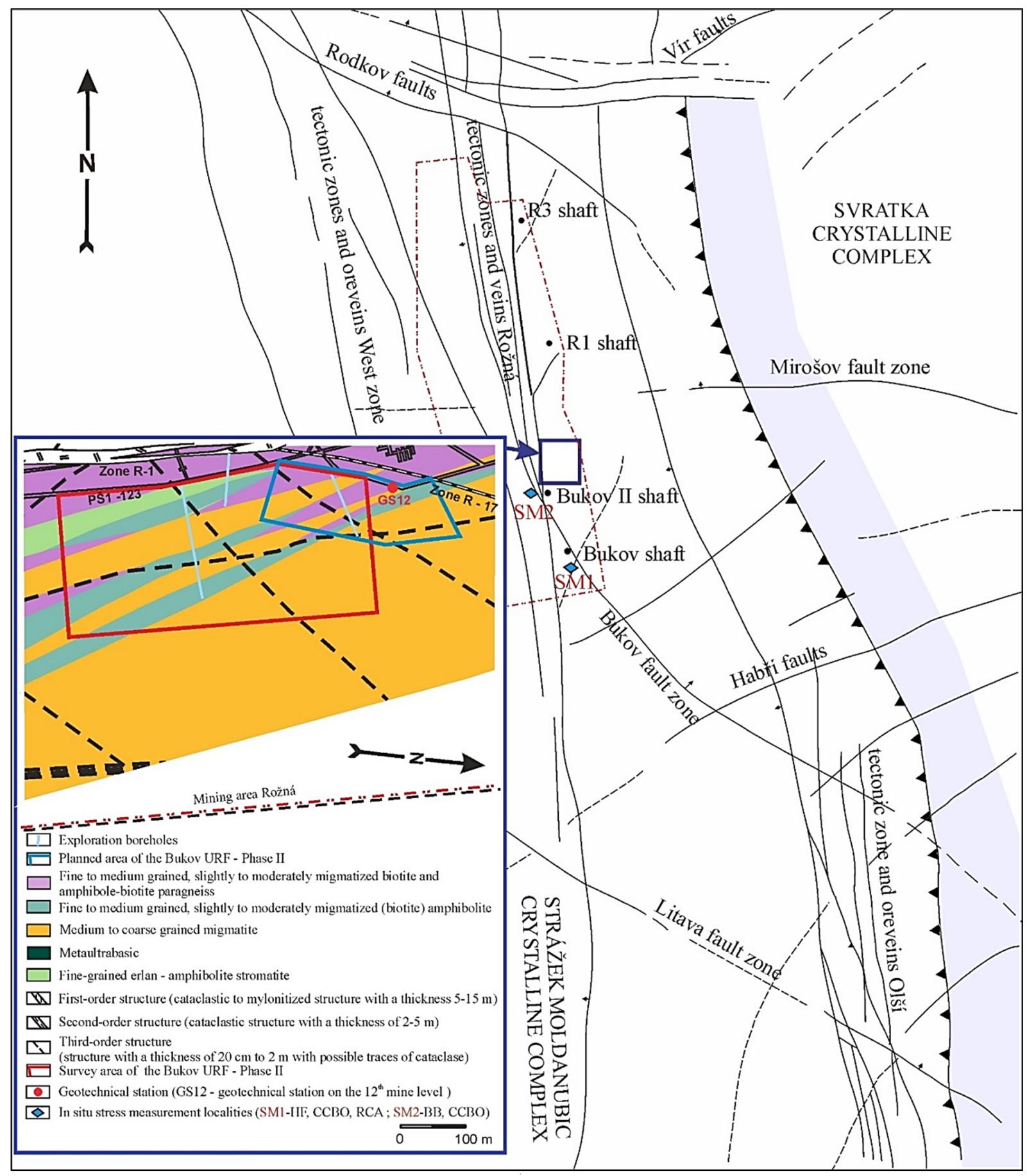

Fig. 2.1 Main fault structures and geological condition in the area of interest (Patocka and Jaros, 2020; Ptáček et al., 2013).

effects of joint spacing, length and stiffness, as well as the scale effect, complicated calibration is needed to select the appropriate model properties (Sainsbury and Sainsbury, 2017). Despite some limitations of the Hoek-Brown criterion e.g. the ignorance of the intermediate principal stress and rock anisotropy, it has been applied in many projects around the world and has been found to provide satisfactory estimates (Hoek and Brown, 2019). Hence, the Hoek-Brown model was adopted in this paper.
Based on the testing results, the Hoek-Brown failure envelope was determined for these samples using RocData toolkit (Rocscience Inc., 2017). The Hoek-Brown parameters for three different loading directions were then averaged to obtain the general failure envelopes for the quasi-homogeneous lithological unit. An example is illustrated in Figure 2.2. 


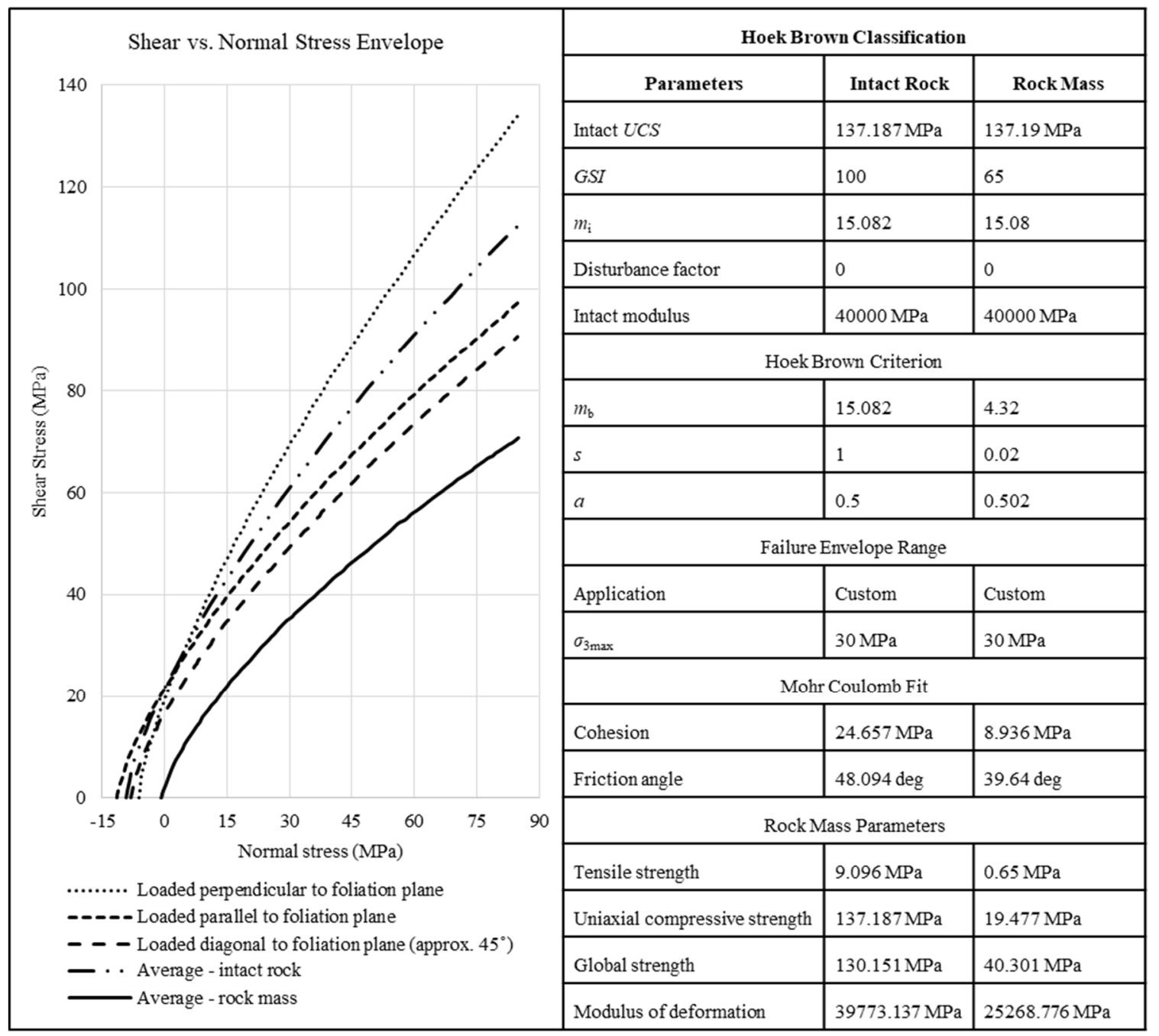

Fig. 2.2 Example for generating the average Hoek-Brown failure envelopes (sample V22).

Table 2.1 Average values of physical-mechanical properties of selected intact rocks from Rožná mine area (Bukovská et al., 2020; Souček et al., 2018).

\begin{tabular}{llccc}
\hline Property & Unit & sample T3 & sample V22-R3 & sample V22 \\
\hline Lithology & - & $\begin{array}{c}\text { Biotite-amphibole } \\
\text { gneiss }\end{array}$ & $\begin{array}{c}\text { Biotite } \\
\text { migmatite }\end{array}$ & $\begin{array}{c}\text { Sillimanite-biotite } \\
\text { migmatite }\end{array}$ \\
\hline Bulk density, $\rho$ & $\mathrm{kg} / \mathrm{m}^{3}$ & 2836 & 2742 & 2635 \\
$\mathrm{UCS}, \sigma_{\mathrm{ci}}-$ direction K & $\mathrm{MPa}$ & 165 & 165 & 160 \\
$\mathrm{UCS}, \sigma_{\mathrm{ci}}$-direction $\mathrm{P}$ & $\mathrm{MPa}$ & 195 & 126 & 111 \\
$\mathrm{UCS}, \sigma_{\mathrm{ci}}$ - direction $\mathrm{S}$ & $\mathrm{MPa}$ & 147 & 74 & 82 \\
Young's modulus, $E_{\mathrm{i}}(\mathrm{K})$ & $\mathrm{GPa}$ & 45 & 41 & 41 \\
Young's modulus, $E_{\mathrm{i}}(\mathrm{P})$ & $\mathrm{GPa}$ & 56 & 54 & 44 \\
Young's modulus, $E_{\mathrm{i}}(\mathrm{S})$ & $\mathrm{GPa}$ & 49 & 29 & 32 \\
Poisson ratio, $v(\mathrm{~K})$ & - & 0.15 & 0.17 & 0.19 \\
Poisson ratio, $v(\mathrm{P})$ & - & 0.17 & 0.16 & 0.17 \\
Poisson ratio, $v(\mathrm{~S})$ & - & 0.14 & 0.12 & 0.1 \\
Splitting tensile strength, $\sigma_{\mathrm{ti}}(\mathrm{K})$ & $\mathrm{MPa}$ & 12.0 & 7.8 & 6.2 \\
Splitting tensile strength, $\sigma_{\mathrm{ti}}(\mathrm{P})$ & $\mathrm{MPa}$ & 12.8 & 12.7 & 11.1 \\
Splitting tensile strength, $\sigma_{\mathrm{ti}}(\mathrm{S})$ & $\mathrm{MPa}$ & 10.9 & 10.4 & 8.1 \\
\hline
\end{tabular}

Note: UCS - uniaxial compressive strength; $\mathrm{K}$ - direction of loading perpendicular to foliation plane; $\mathrm{P}$ - direction of loading parallel to foliation plane; $\mathrm{S}$ - direction of loading diagonal (approximately $45^{\circ}$ ) to metamorphic foliation plane; sample T3 - level 12, Bukov URF - Phase I, access gallery BZ-XIIJ; sample V22-R3 - level 22, R3 shaft; sample V22 - level 22, R7S shaft. 
To extrapolate the averaged Hoek-Brown parameters from intact rock samples to filed-scale values, the Geological Strength Index (GSI) of the rock mass was employed (Hoek et al., 2013). Structural characteristics including persistence, roughness, undulation, and opening and filling of rock mass discontinuities were previously documented on the uncovered opening walls within the Bukov URF Phase I (Bukovská et al., 2019; Souček et al., 2018). The GSI was then calculated using two different methods:

$G S I=1.5$ Cond $_{89}+R Q D / 2$

and

$G S I=52 J_{\mathrm{r}} /\left(J_{\mathrm{a}}+J_{\mathrm{r}}\right)+R Q D / 2$

where, $R Q D$ is Rock Quality Designation index value, JCond $_{89}$ is Joint Condition rating according to Bieniawski (1989) and the joint roughness number $J_{\mathrm{r}}$ and joint alteration number $J_{\mathrm{a}}$ are parameters in the $Q$-system (Barton et al., 1974).

The estimated $R Q D$ value for the rock mass of the whole Rožná uranium mine area is mostly between 60-65\%, peak up to 70 to $80 \%$ (Bukovská et al., 2020; Bukovská et al., 2019; Souček et al., 2018; Souček et al., 2017; Vavro et al., 2015). However, Patocka and Jaros (2020) state an average $R Q D$ value of up to about $86 \%$ in the area of interest. We have chosen the $R Q D$ value of $60 \%$ for the calculation of GSI out of concern for safety. The values of other parameters $\left(\right.$ JCond $_{89}, J_{\mathrm{r}}$ and $J_{\mathrm{a}}$ ) were determined from a distribution analysis of the discontinuity factors (e.g. persistence, roughness, etc.) expressed by a weighted average. Table 2.2 shows the determined geological input values for the calculation of GSI under the most probable occurrences of $R Q D$ values at Bukov URF - Phase II. It is clear that at the condition of $R Q D=60 \%, G S I$ varies in the range of 63-67. Hence, a value of 65 was chosen for estimating the filed-scale geomechanical properties of the above-mentioned intact rock samples. The obtained Hoek-Brown parameters for the rock mass were further averaged to describe the quasi-homogeneous rock mass for the numerical modelling. In this way, both the anisotropic rock fabric (foliation) and the geological structure are taken into account. The failure envelope representing the macro-scale rock mass properties corresponding to the sample V22 (see Table 2.1) was also shown in Figure 2.2.

Final input properties for the Hoek-Brown model are summarised in Table 2.3.

\subsection{STRESS STATE OF ROCK MASSES}

One of the typical features of the rock mass at the Bukov region is relatively significant anisotropy, verified both physically (e.g. ultrasonic wave velocity, thermal conductivity and specific heat capacity) and mechanically (e.g. splitting tensile strength and uniaxial compressive strength) (Bukovská et al., 2020; Bukovská et al., 2019; Souček et al., 2018; Vavro et al., 2015). The high degree of textural anisotropy of rocks, as well as the relatively significant disturbance of the rock mass by ductile and brittle tectonics, result in the in situ stress field of the rock mass in this region as highly anisotropic.

Over the years abundant in situ stress measurements have been conducted in the Rožná mine region, with the measurement depth ranging from $520 \mathrm{~m}$ to $1183 \mathrm{~m}$, as summarised in Table 2.4 (Bukovská et al., 2020; Souček et al., 2018). Although four different methods have been used for better reliability, i.e. borehole breakout (BB), hydraulic fracturing (HF), compact conical ended borehole overcoring (CCBO), and roadway convergence analysis (RCA), considerable scatter is still observed. Taking into account that a "stress decoupling" effect may exist causing significant difference in stresses at shallow depth and at great depth (Stephansson and Zang, 2012), and the fact that Bukov URF - Phase II is located at a depth of around $550 \mathrm{~m}$, the stress data obtained at 500-600 m depth were selected for the in situ stress estimation for the Bukov URF - Phase II modelling.

Figure 2.3 plots the ratios of average horizontal stress $\left(\sigma_{\mathrm{H}}+\sigma_{\mathrm{h}}\right) / 2$ to vertical stress $\sigma_{\mathrm{v}}$ from the selected measurements compared with the ratio limits suggested by Brown and Hoek (1978). It is clear that all the data lie within the boundary limit, suggesting the reliability of the measurement data to a great extent.

Table 2.2 Estimated quality parameters of Bukov URF - Phase II rock mass for the calculation of GSI.

\begin{tabular}{|c|c|c|c|c|}
\hline \multicolumn{5}{|c|}{ BZ-XIIJ access gallery (mapped approx. $220 \mathrm{~m}$, evaluated approx. 650 discontinuities) } \\
\hline & & $Q D(\%)$ & GSI (from Eq. 2.1) & GSI (from Eq. 2.2) \\
\hline JCond $_{89}$ & 24.7 & 60 & 67.1 & 64.2 \\
\hline$J_{\mathrm{r}}$ & 2.30 & 70 & 72.1 & 69.2 \\
\hline$J_{\mathrm{a}}$ & 1.21 & 80 & 77.1 & 74.2 \\
\hline \multicolumn{5}{|c|}{ Iain laboratory tunnel BZ $\mathrm{B}$-XII (mapped approx. $90 \mathrm{~m}$, evaluated approx. 273 discontinuities) } \\
\hline & & $R Q D(9$ & GSI (from Eq. 2.1) & GSI (from Eq. 2.2) \\
\hline JCond $_{89}$ & 24.5 & 60 & 66.8 & 62.7 \\
\hline$J_{\mathrm{r}}$ & 2.13 & 70 & 71.8 & 67.7 \\
\hline$J_{\mathrm{a}}$ & 1.26 & 80 & 76.8 & 72.7 \\
\hline
\end{tabular}


Table 2.3 Rock mechanical properties for the Hoek-Brown model.

\begin{tabular}{lcc}
\hline \multicolumn{1}{c}{ Property } & Unit & Value \\
\hline Geological Strength Index, GSI & - & 65 \\
Deformation modulus, $E_{\mathrm{b}}$ & $\mathrm{GPa}$ & 28 \\
Poisson's ratio, $v$ & - & 0.2 \\
Elastic bulk modulus, $K$ & $\mathrm{GPa}$ & 15.56 \\
Elastic shear modulus, $G$ & $\mathrm{GPa}$ & 11.67 \\
Density, $\rho$ & $\mathrm{kg} / \mathrm{m}^{3}$ & 2700 \\
Hoek-Brown parameter, $a$ & - & 0.502 \\
Hoek-Brown parameter, $m_{\mathrm{b}}$ & - & 3.816 \\
Hoek-Brown parameter, $s$ & - & 0.02 \\
Uniaxial compressive strength for intact rock, $\sigma_{\mathrm{ci}}$ & $\mathrm{MPa}$ & 147.86 \\
Tensile strength for rock masses, $\sigma^{\mathrm{t}}$ & $\mathrm{MPa}$ & 0.8 \\
\hline
\end{tabular}

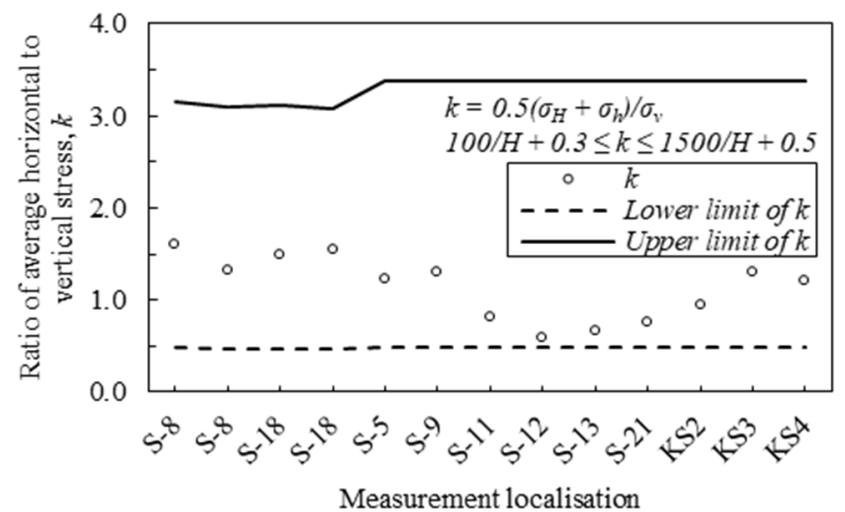

Fig. 2.3 Ratios of average horizontal stress to vertical stress lying within the range found by Brown and Hoek (1978).

\subsubsection{INTERPRETATION OF IN SITU STRESS DATA 2.4.1.1. VERTICAL STRESS}

It has been proved that the vertical stress can be estimated by overburden weight in most cases (Amadei and Stephansson, 1997; Brown and Hoek, 1978; Herget, 1974; Zang and Stephansson, 2010). In the region of interest, no apparent geological anomalies for example young tectonics, volcanism or rough topography exist. Hence, the vertical stress was estimated through theoretical calculation:

$\sigma_{v}=\rho g H$

where, $\rho$ is the average density of rock given as $2700 \mathrm{~kg} / \mathrm{m}^{3}, g$ is gravity i.e. $9.8 \mathrm{~N} / \mathrm{kg}$, and $H$ is depth (550 m).

Note that the vertical stress measured from CCBO method is predominantly lower compared with the theoretically calculated value (i.e. 14.6 MPa), possibly due to over-coring-induced microcracking and mining-induced fractures.

In general, the role vertical stress plays in the in situ stress tensor can be roughly estimated based on the major fault patterns (thrust, strike-slip, or normal) in the region (Anderson, 1905). However, complex tectonic structures exist in the planned Bukov URF -
Phase II region, and different fault zones crosscut each other, often have been repeatedly reactivated and thus the fault planes often bear several generations of striation (Bukovská et al., 2019). Clear determination of primary kinematics is therefore nearly impossible. Hence, it is very difficult to determine whether the vertical stress acts as maximum, intermediate or minimum principal stress in this region, due to the occurrence of complex geological structures.

\subsubsection{HORIZONTAL STRESSES}

Since the in situ stress characteristics are compiled from multiple methodologies, it is impracticable to rigorously assign errors purely using statistical methods. In addition, the measurement data show significant scatter. Hence, it is better to estimate the state of stress on the trends in the data rather than on individual test results. The ratio between the maximum and intermediate principal stress $\left(R_{1}\right)$ and the mean principal stress $(M)$ were adopted to back-calculate the stress magnitudes (Martin, 2007), instead of directly taking the average values of each stress components. As a result, three different in situ stress scenarios could be derived, depending on the role the vertical stress plays, as summarised in Table 2.5. 
Table 2.4 Detailed in situ stress measurement data (Bukovská et al., 2020; Souček et al., 2018).

\begin{tabular}{|c|c|c|c|c|c|c|c|c|c|}
\hline Localization & Method & Depth & $S_{\mathrm{V}}-$ theoretical $/$ measured & $S_{\mathrm{H}}$ & $S_{\mathrm{h}}$ & $S_{\mathrm{H}}$ orientation $\left({ }^{\circ}\right)$ & \multicolumn{3}{|c|}{ Ratio $S_{\mathrm{v}}: S_{\mathrm{H}}: S_{\mathrm{h}}$} \\
\hline GS20/1 & $\mathrm{BB}$ & 907 & 24.0 & - & - & 177 & - & - & - \\
\hline GS20/1 & $\mathrm{BB}$ & 916 & 24.3 & - & - & 175 & - & - & - \\
\hline GS20/1 & $\mathrm{BB}$ & 921 & 24.4 & - & - & 150 & - & - & - \\
\hline GS20/1 & BB & 936 & 24.8 & - & - & 170 & - & - & - \\
\hline GS20/2 & $\mathrm{BB}$ & 932 & 24.7 & - & - & 170 & - & - & - \\
\hline GS20/1 & $\mathrm{BB}$ & 907 & 24.0 & - & - & 177 & - & - & - \\
\hline $\mathrm{S}-8$ & $\mathrm{HF}$ & 565 & 15.0 & 31 & 17 & 180 & 1.0 & 2.1 & 1.1 \\
\hline S-8 & $\mathrm{HF}$ & 578 & 15.3 & 27 & 13.5 & 21 & 1.0 & 1.8 & 0.9 \\
\hline S-18 & $\mathrm{HF}$ & 575 & 15.2 & 29.3 & 15.9 & 30 & 1.0 & 1.9 & 1.0 \\
\hline S-18 & $\mathrm{HF}$ & 583 & 15.4 & 31.5 & 16.5 & 28 & 1.0 & 2.0 & 1.1 \\
\hline S-5 & $\mathrm{CCBO}$ & 520 & 5.7 & 8.1 & 5.9 & 80 & 1.0 & 1.4 & 1.0 \\
\hline S-9 & $\mathrm{CCBO}$ & 520 & $\overline{7.0}$ & 15.4 & 2.9 & 15 & 1.0 & 2.2 & 0.4 \\
\hline S-11 & $\mathrm{CCBO}$ & 520 & $1 \overline{0.6}$ & 10.1 & 7.2 & 15 & 1.0 & 1.0 & 0.7 \\
\hline S-12 & $\mathrm{CCBO}$ & 520 & 13.9 & 11.2 & 5.3 & 30 & 1.0 & 0.8 & 0.4 \\
\hline S-13 & $\mathrm{CCBO}$ & 520 & 14.8 & 14.6 & 5.1 & 228 & 1.0 & 1.0 & 0.3 \\
\hline S-21 & $\mathrm{CCBO}$ & 520 & 7.9 & 7 & 4.9 & 228 & 1.0 & 0.9 & 0.6 \\
\hline $\mathrm{KS} 2$ & RCA & 520 & 13.8 & 16.5 & 9.6 & 30 & 1.0 & 1.2 & 0.7 \\
\hline KS3 & $\mathrm{RCA}$ & 520 & 13.8 & 31.7 & 4.1 & 41 & 1.0 & 2.3 & 0.3 \\
\hline $\mathrm{KS} 4$ & $\mathrm{RCA}$ & 520 & 13.8 & 30.3 & 2.8 & 41 & 1.0 & 2.2 & 0.2 \\
\hline
\end{tabular}

Note: $S_{\mathrm{v}}$ - vertical rock mass stress component; $S_{\mathrm{H}}-$ major horizontal rock mass stress component; $S_{\mathrm{h}}-$ minor horizontal rock mass stress component; GS20/1 - geotechnical station situated on the level 20 of the Rožná mine (Bukovská et al., 2020); S-5, S-8, S-9, S-11, S-12, S-13, and S-18 - boreholes evaluated within the Bukov URF - Phase I construction (Bukovská et al., 2020; Bukovská et al., 2019); KS2, KS3, and KS4 - convergence stations with convergence measurements used for reverse analysis of the rock mass stress state assessment (Bukovská et al., 2019; Souček et al., 2018).

Table 2.5 Three different scenarios of in situ stress states depending on the role of the vertical stress.

\begin{tabular}{cccc}
\hline Scenarios & Maximum principal stress, & Intermediate principal stress, & Minimum principal stress, \\
& $\sigma_{1}$ & $\sigma_{2}$ & $\sigma_{3}$ \\
\hline I: $\sigma_{3}=\sigma_{\mathrm{v}}$ & $R_{1}\left(3 M-\sigma_{\mathrm{v}}\right) /\left(1+R_{1}\right)$ & $R_{1}\left(3 M-\sigma_{\mathrm{v}}\right) /\left(1+R_{1}\right)$ & $\sigma_{\mathrm{v}}$ \\
II: $\sigma_{2}=\sigma_{\mathrm{v}}$ & $R_{1} \sigma_{\mathrm{v}}$ & $\sigma_{\mathrm{v}}$ & $3 M-\left(1+R_{1}\right) \sigma_{\mathrm{v}}$ \\
III $: \sigma_{1}=\sigma_{\mathrm{v}}$ & $\sigma_{\mathrm{v}}$ & $\sigma_{\mathrm{v}} / R_{1}$ & $3 M-\left(1+1 / R_{1}\right) \sigma_{\mathrm{v}}$ \\
\hline
\end{tabular}

Table 2.6 Statistical data of mean principal stress and principal stress ratios.

\begin{tabular}{lll}
\hline Data analysis & Mean & Standard deviation \\
\hline Mean principal stress, $M$ & $13.8 \mathrm{MPa}$ & $5.4 \mathrm{MPa}$ \\
Principal stress ratio $R_{1}: \sigma_{1} / \sigma_{2}$ & 1.62 & 0.47 \\
Principal stress ratio $R_{2}: \sigma_{1} / \sigma_{3}$ & 3.37 & 2.91 \\
\hline
\end{tabular}

Based on Table 2.4, the average values and standard deviations of each parameter are shown in Table 2.6.

From the measurement results it can be stated that the rock mass is relatively complicated in terms of the orientation and magnitude of the stress field. The local variability of the interpreted results is manifested mainly in the orientation. The global evaluation of the whole group of current and previously performed measurements shows the orientation of the main component of horizontal stress $\left(S_{\mathrm{H}}\right)$ is in the direction of NW-SE to N-S, but the directions NNE-SSW are not exceptional either. Hence, the maximum horizontal stress orientation was simplified as $\mathrm{N}-\mathrm{S}$.

\subsubsection{POSSIBLE SCENARIOS OF IN SITU STRESS STATE}

The rock mass behaviour and stability of the Bukov URF - Phase II was then investigated at the most probable cases of in situ stress states based on Tables 2.5-2.6, with the mean stresses and principal stress ratios ranging by either-side one standard deviation. Considering that the ratio $R_{1}$ ranges from 1.15 to 2.09 , four different levels of $R_{1}(1.2,1.4,1.6$, 
Table 2.7 Simulation scenarios of different in situ stress states.

\begin{tabular}{|c|c|c|c|c|c|c|c|}
\hline Scenarios & Subcase & $R_{1}=\sigma_{1} / \sigma_{2}$ & $\sigma_{1}$ & $\sigma_{2}$ & $\sigma_{3}$ & $M$ & $a_{\mathrm{s}}$ \\
\hline \multirow{4}{*}{ I } & $\# 1$ & 1.2 & 22.9 & 19.1 & \multirow{4}{*}{14.6} & \multirow{4}{*}{18.9} & 0.3717 \\
\hline & $\# 2$ & 1.4 & 24.5 & 17.5 & & & 0.3850 \\
\hline & \#3 & 1.6 & 25.8 & 16.1 & & & 0.4055 \\
\hline & $\# 4$ & 1.8 & 27.0 & 15.0 & & & 0.4223 \\
\hline \multirow{4}{*}{ II } & $\# 1$ & 1.2 & 17.5 & \multirow{4}{*}{14.6} & 13.8 & \multirow{4}{*}{15.3} & 0.3294 \\
\hline & \#2 & 1.4 & 20.4 & & 10.9 & & 0.3716 \\
\hline & \#3 & 1.6 & 23.4 & & 7.9 & & 0.4448 \\
\hline & $\# 4$ & 1.8 & 26.3 & & 5.0 & & 0.5627 \\
\hline \multirow{4}{*}{ III } & $\# 1$ & 1.2 & \multirow{4}{*}{14.6} & 12.2 & 2.6 & \multirow{4}{*}{9.8} & 0.4995 \\
\hline & $\# 2$ & 1.4 & & 10.4 & 4.4 & & 0.3514 \\
\hline & \#3 & 1.6 & & 9.1 & 5.7 & & 0.2763 \\
\hline & $\# 4$ & 1.8 & & 8.1 & 6.7 & & 0.2350 \\
\hline
\end{tabular}

and 1.8) was selected while keeping the mean stress $M$ constant for each scenario. The corresponding values of the three principal stresses in each subcase are listed in Table 2.7 .

\section{NUMERICAL SIMULATION \\ 3.1. MODEL GENERATION AND BOUNDARY CONDITIONS}

The Itasca software FLAC3D (Itasca Consulting Group, 2012) was adopted to analyse the stability of the planned underground research facility. The well-known Hoek-Brown model was employed to control the rock mass behaviour in this project. The failure mode was assumed as ductile failure (elasticperfectly plastic) for a preliminary evaluation of the overall stability. The material properties $\sigma_{\mathrm{ci}}, m_{\mathrm{b}}, s$ and $a$ were assumed to remain constant after the onset of plastic yield, as shown in Table 2.3.

The model is fixed on the bottom boundary while free on the top and side boundaries. A vertical stress $\sigma_{\mathrm{v}}=14.6 \mathrm{MPa}$ is applied on the top surface. The maximum horizontal stress points north which coincides with the positive y-direction of the current model, and the minimum horizontal stress is applied in the x-direction. In terms of the horizontal stress magnitudes, three different scenarios with each having four levels of the principal stress ratio $R_{1}$ were studied, as shown in Table 2.7.

The model dimension was determined carefully to eliminate the boundary effect. The top and bottom boundary of the model were set as ten excavation height away from the excavation periphery (Itasca Consulting Group, 2012), i.e. the model has a height of $84 \mathrm{~m}$. To select the appropriate lateral boundary dimension, a series of parallel model (Fig. 3.1) with different values of width/length were generated. All the designed roadways and laboratory chambers were excavated simultaneously and run to equilibrium. Instead of using the Hoek-Brown model and complex in situ stress conditions, the conventional
Mohr-Coulomb model was adopted for investigating the boundary effect, and the boundary stress condition is simply determined as

$\sigma_{\mathrm{H}}=\sigma_{\mathrm{h}}=\sigma_{\mathrm{v}} v /(1-v)$

where $\sigma_{\mathrm{H}}$ and $\sigma_{\mathrm{h}}$ are the maximum and minimum horizontal stress, respectively, and the passion ratio $v$ is given as 0.2 .

Figure 3.2 shows the change of maximum displacement magnitude of the models with varying lateral boundary dimensions. It is clear that the lateral boundary effect on the model displacement is minor. The variation of the maximum displacement magnitude is within $1 \mathrm{~mm}$ when the lateral distance between the boundaries and the excavation region increased from $50 \mathrm{~m}$ to $300 \mathrm{~m}$. Considering the calculation efficiency, $L=50 \mathrm{~m}$ was selected and a corresponding dimension of $224 \times 336 \times 84 \mathrm{~m}$ was finally determined for the $3 \mathrm{D}$ model. A total of 583,233 zones are contained in the model, with the unit zone volume ranging from $8.5 \mathrm{~cm}^{3}$ to $130 \mathrm{~m}^{3}$. To ensure the continuity of model behaviour between different sub-grids, the "interface" element was applied to connect the adjoining primitive shapes having different zone size / face shape. Both the normal and shear stiffness were set as 10 times the apparent stiffness of the adjoining zone i.e. $\max \left[(K+4 G / 3) / \Delta \mathrm{z}_{\min }\right]$ according to the FLAC3D manual (Itasca consulting group, 2012), where $K$ and $G$ are the bulk and shear moduli, respectively, and $\Delta \mathrm{z}_{\text {min }}$ is the smallest width of an adjoining zone in the normal direction, with the tensile strength given as a very high value of $10 \mathrm{GPa}$.

\subsection{MODELLING PROCEDURE}

The modelled roadways and chambers were excavated step by step. As shown in Figure 3.3, the excavation includes ten sequences. Firstly, the main roadway remained from previous mining works were excavated. The roadway branch in the furthest south 


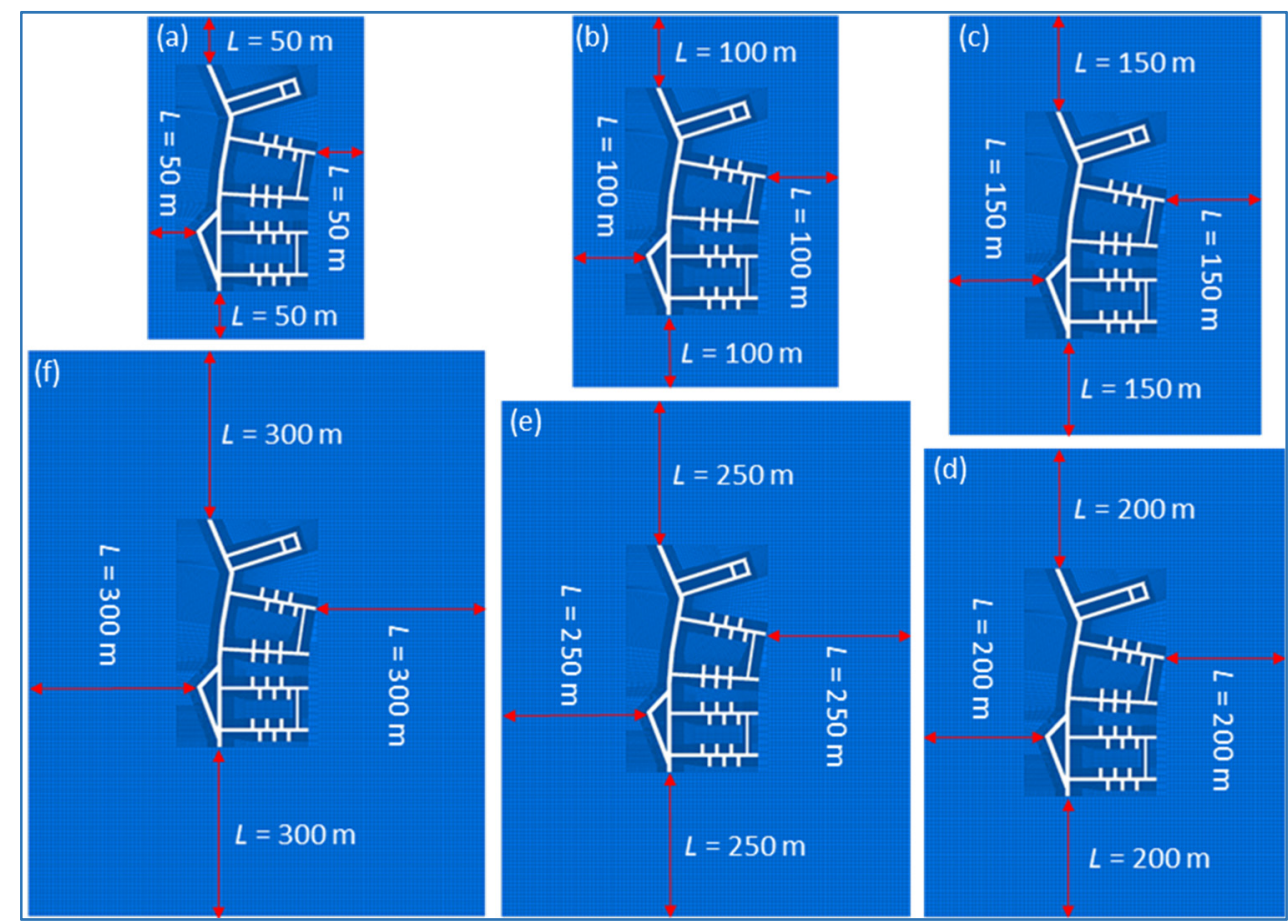

Fig. 3.1 Plane view of the model geometry with different lateral boundary dimensions.

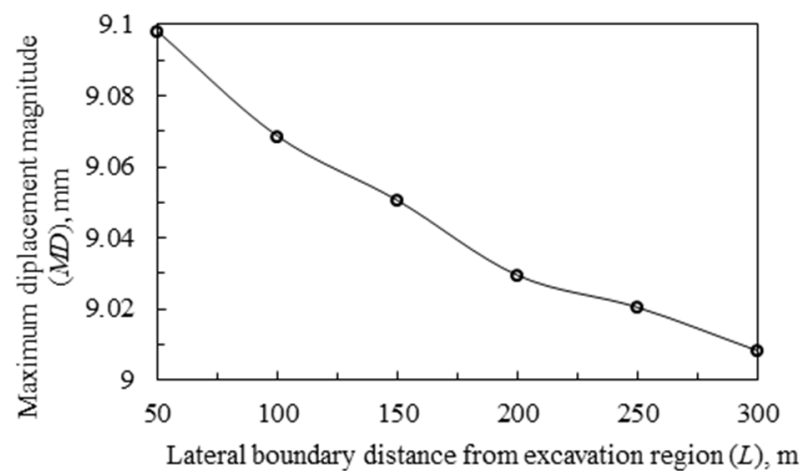

Fig. 3.2 Lateral boundary effect on the maximum displacement magnitude after a whole-stage excavation.

part (RoadwayL8) were then excavated, followed by the next branch the northern vicinity (RoadwayL7), and a ventilation roadway (Ventilation7-8) connecting these two branches was developed afterwards. Next, the excavation of the third and fourth branches (RoadwayL6 and RoadwayL5, respectively) were conducted, following the second ventilation roadway (Ventilation5-6) later on. After that, the last group of roadways and chambers (RoadwayL4) were excavated sequentially, as depicted in Figure 3.3. The model was run to equilibrium after each sequence. Both velocity and displacement of the whole model were reset to zero after the main roadway excavation, so that the net increments resulted from the new excavations can be directly observed. All the codes and FISH subroutines during the modelling can be provided by request.

\subsection{MODELLING RESULTS AND DISCUSSION}

\subsubsection{MINIMUM STRENGTH-STRESS RATIO AND} MAXIMUM DISPLACEMENT MAGNITUDE

As with all other engineering projects, the FoS is the most common index evaluating the feasibility of the construction design and the stability of the rock mass surrounding the excavations. In the case of underground tunnel excavation, conventional parameters calculating the factor-of-safety index include the current stress state's proximity to failure, and displacement or convergence compared with a specified threshold. The minimum strength-stress ratio $(M S R)$ and the maximum displacement magnitude $(M D)$ inside the whole model were hence analysed.

As shown in Figure 3.4, the value of MSR varies considerably as the model-input in situ stress state changes, ranging from 1.08 to 1.56 . However, due to 


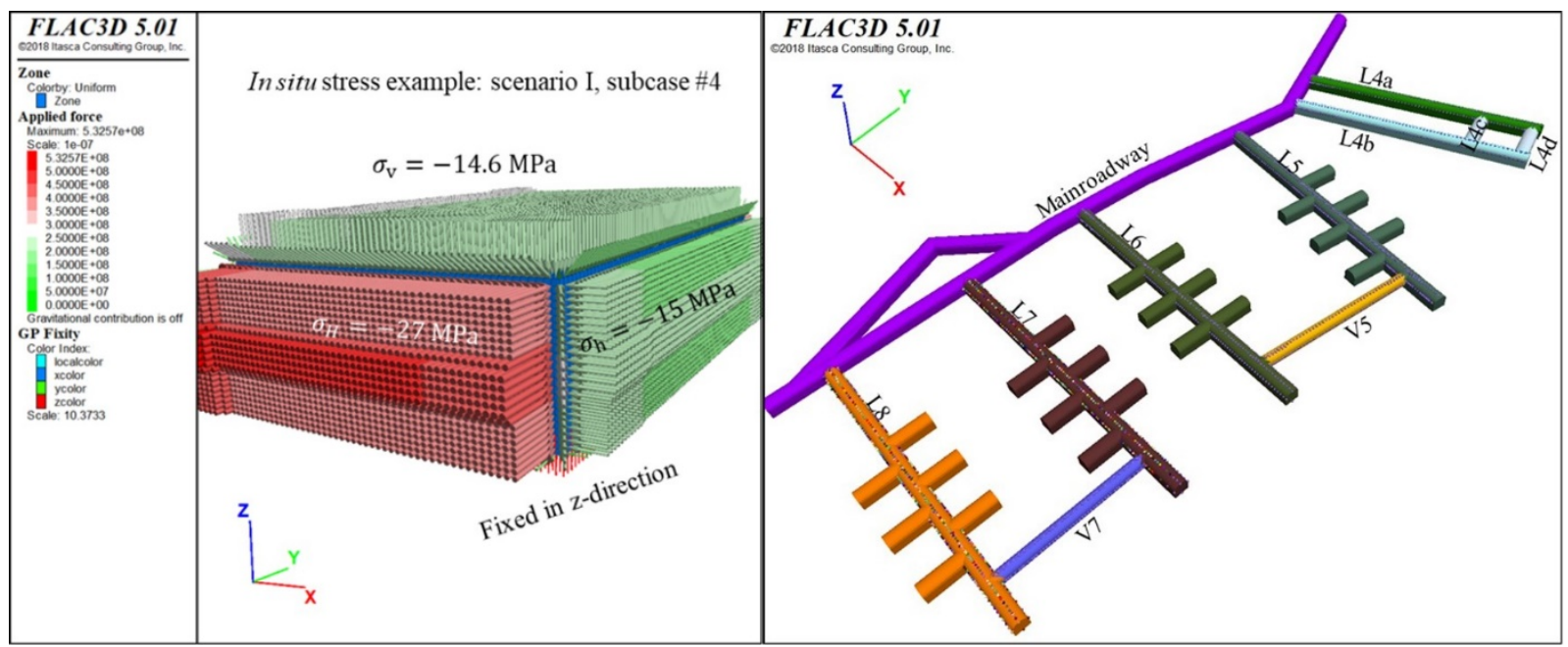

Fig. 3.3 Model generation and excavation sequences of the designed underground research facility.
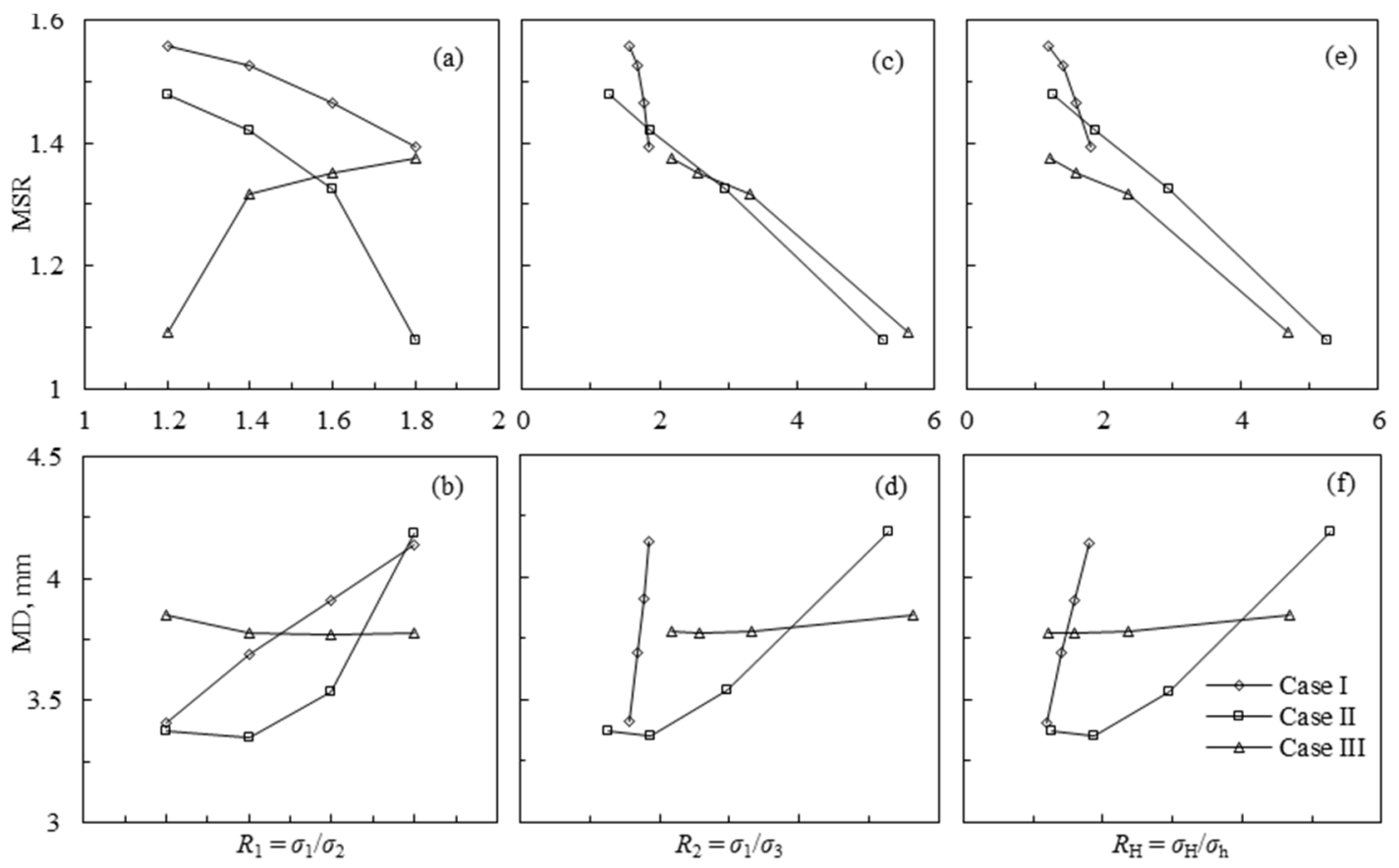

Fig. 3.4 Minimum strength-stress ratio and maximum displacement magnitude vs. principal stress ratios under different in situ stress conditions.

the strength-stress ratio larger than unity and the high modulus of rock masses, the displacement magnitude varies only within $1 \mathrm{~mm}$, and $4.2 \mathrm{~mm}$ maximum. In case I where the vertical stress acts as the minimum principal stress, $M S R$ decreases gradually as $R_{1}$ (i.e. $\sigma_{1} / \sigma_{2}$ ) increases, whereas $M D$ increases accordingly. The same trend goes for case II where the vertical stress plays the role of intermediate principal stress. However, $M S R$ increases with the increase of $R_{1}$ and $M D$ decreases slightly in case III, where the maximum component of the in situ stress tensor is vertical. On the other hand, the variation trends of $M S R$ and $M D$ respectively are consistent in all cases when plotted against the principal stress ratio $R_{2}\left(\sigma_{1} / \sigma_{3}\right)$ and the horizontal stress ratio $R_{\mathrm{H}}\left(\sigma_{\mathrm{H}} / \sigma_{\mathrm{h}}\right)$. As shown in Figure 3.4 (c-f), the value of $M S R$ decreases while $M D$ increases in all three scenarios, when $R_{2}$ and $R_{\mathrm{H}}$ increase. This is understandable as the increased $R_{2}$ or $R_{\mathrm{H}}$ lead to either the increase in $\sigma_{1}$ (case I and II) or the decrease in $\sigma_{3}$ (case III). According to the HoekBrown criterion as depicted in Eq. (3.7), the decrease in $\sigma_{3}$ causes the drop in the compressive strength $\sigma_{1 \mathrm{~m}}$ of the rock mass. Either an increase in $\sigma_{1}$ or decrease in $\sigma_{3}$ results in decreased $\sigma_{1 \mathrm{~m}} / \sigma_{1}$ i.e. the strengthstress ratio. On the other hand, the increase in $R_{1}$ causes increased $\sigma_{1}$ in case I where $\sigma_{3}$ remains constant, increased $\sigma_{1}$ in case II where $\sigma_{3}$ decreases, and increased $\sigma_{3}$ in case III where $\sigma_{1}$ remains constant. 

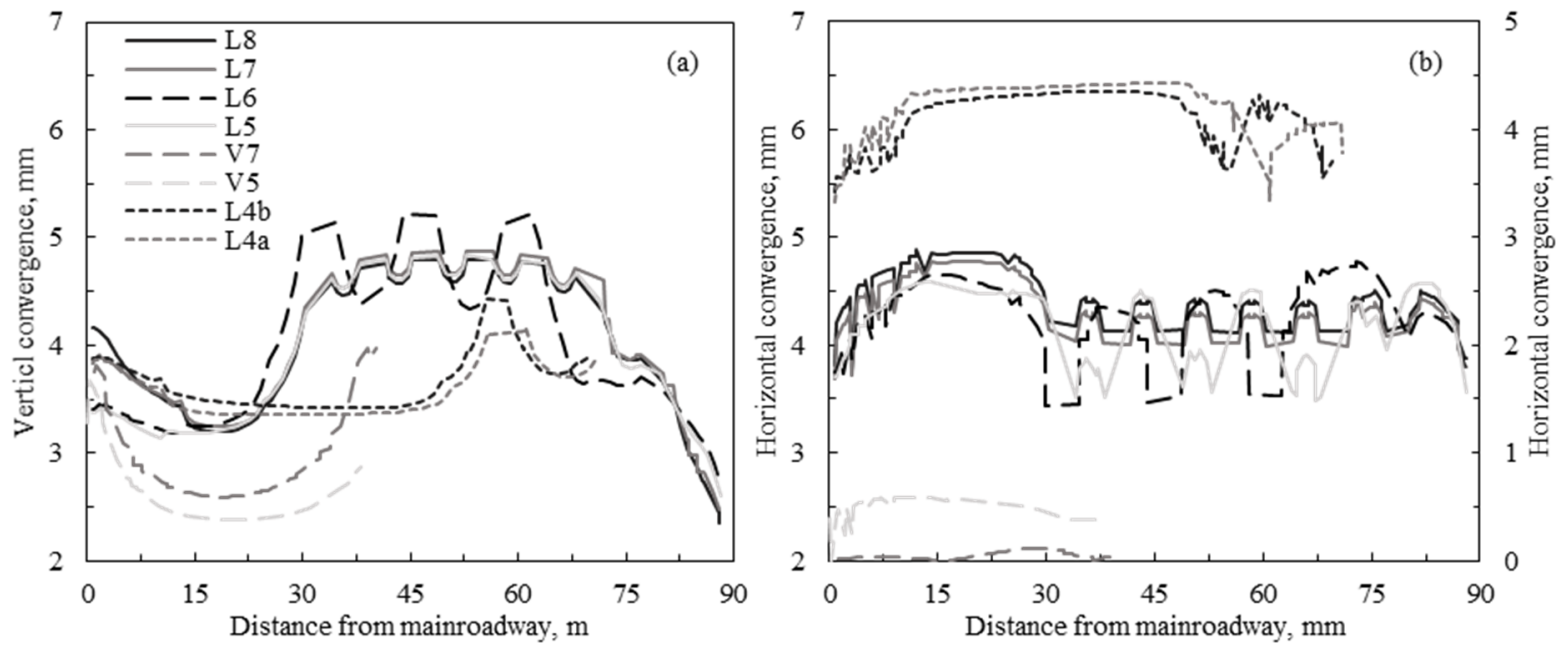

Fig. 3.5 Roadway convergence distribution in case I with $R_{1}=1.2$.

Note: curves in (b) for ventilation channels (V7 and V5) and the major roadways L4(a-b) are plotted against the right-side (secondary) y-axis for the purpose of distinct demonstration.

As a consequence, the variations of $M S R$ and $M D$ in case III show 'abnormal' trends with increased $R_{1}$, as plotted in Figures 3.4(a-b).

$\sigma_{1 \mathrm{~m}}=\sigma_{3}+\sigma_{c i}\left\{m_{b} \frac{\sigma_{3}}{\sigma_{c i}}+s\right\}^{a}$

In addition, with the drops of the mean stress $M$, the absolute value of the curve slope also decreases in terms of both $M S R$ and $M D$, largely depending on the varying trends of the in-situ stress dominated $\sigma_{1 \mathrm{~m}} / \sigma_{1}$ at different $M$ levels. This suggests that the influence of $R_{2}$ or $R_{\mathrm{H}}$ on the excavation stability is more significant at higher mean stress levels.

\subsubsection{DISTRIBUTION OF CONVERGENCE AND STRENGTH-STRESS RATIO ALONG ROADWAYS}

To further evaluate the roadway deformation and stability, a series of measurement points were selected on the roadway surface. Four points were chosen in each cross section perpendicular to the roadway axis, located on the roof, floor, left and right ribs respectively, with a cross section interval of roughly $0.5 \mathrm{~m}$. A total of 4556 points were measured, demonstrated as sphere marks in Figure 3.3 (right). The statistical distribution of the horizontal/vertical convergence and the strength-stress ratio were analysed. Since vertical stress keeps constant in all the modelling scenarios, and the horizontal stress ratio $R_{\mathrm{H}}$ has more consistent influence on the FoS related roadway parameters according to the results mentioned above, only $R_{\mathrm{H}}$ is adopted for the analysis in this section.

\subsubsection{CONVERGENCE}

Various researchers have adopted convergence indices to judge the failure or ultimate/serviceability limit state of the excavation (e.g. Heidarzadeh et al., 2021; Zhang and Mitri, 2008; Abdellah et al., 2018). Convergence ratio i.e. the ratio of convergence to the original span of the excavation is commonly employed as the stability criterion. According to the modelling results, the maximum horizontal/wall convergence ratio is $0.18 \%$, while the maximum vertical convergence ratio is $0.15 \%$, which are considered satisfactory in the current project.

(1) The influence of roadway layout on the convergences

Modelling results reveal that the qualitative distribution patterns of convergences depend on the roadway layout characteristics, remaining similar regardless of the changes of in situ stress states. In other words, the excavation-induced stress concentration/release state instead of the in situ stresses dominates the roadway convergence patterns. Figure 3.5 shows the distribution patterns of the roadway convergence in case I $\left(R_{1}=1.2\right)$. Major roadways (i.e. L8, L7, L6, L5 and L4) show curves with troughs and crests along the roadway axes due to intersections with perpendicular chambers. Ventilation channels (i.e. V7 and V5) reveal concave/convex type curves instead. Roadways connected with more numbers of chambers generally have larger convergence, with maximum vertical convergences and minimum horizontal convergences in each roadway located in close proximity to the roadway-chamber intersections. Note that the pattern for the roadway L6 is different from other major roadways due to different chamber layout. In L6, the chambers are symmetrically placed, causing slightly higher vertical convergence at the intersection.

Figure 3.6 plots the maximum value of both vertical and horizontal convergence of each roadway against the horizontal stress ratio $R_{\mathrm{H}}$ at three different in situ stress scenarios. With the increase of $R_{\mathrm{H}}$, the maximum vertical convergence decreased in roadways perpendicular or with larger angle to the direction of maximum horizontal stress (i.e. Y-axis of the model). In ventilation channels where the roadway axis has small angle to the model $\mathrm{Y}$-axis, the trend is opposite. However, the increase of $R_{\mathrm{H}}$ has a consistent 

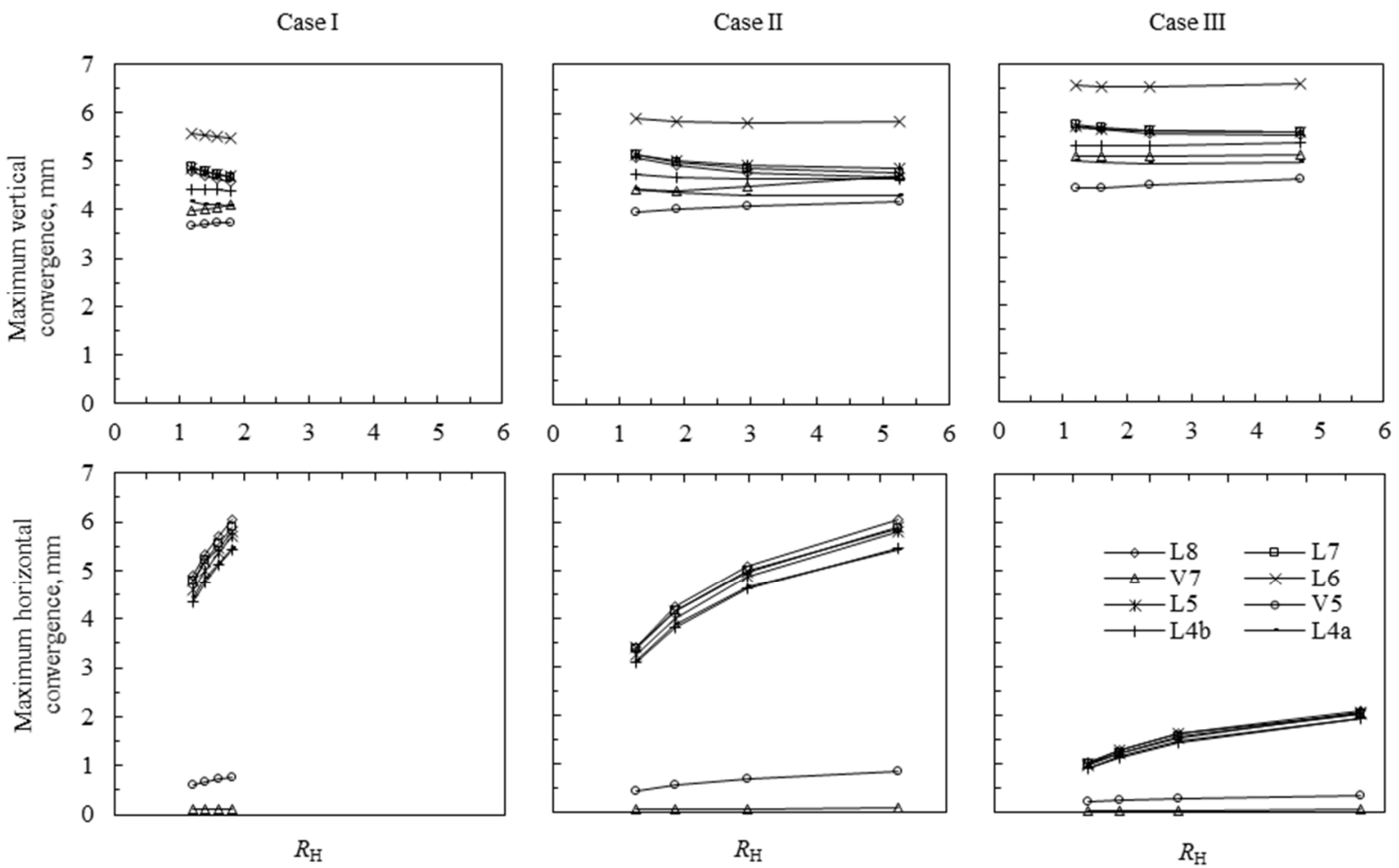

Fig. 3.6 Maximum convergences of each roadway vs. horizontal stress ratios at different in situ stress conditions.
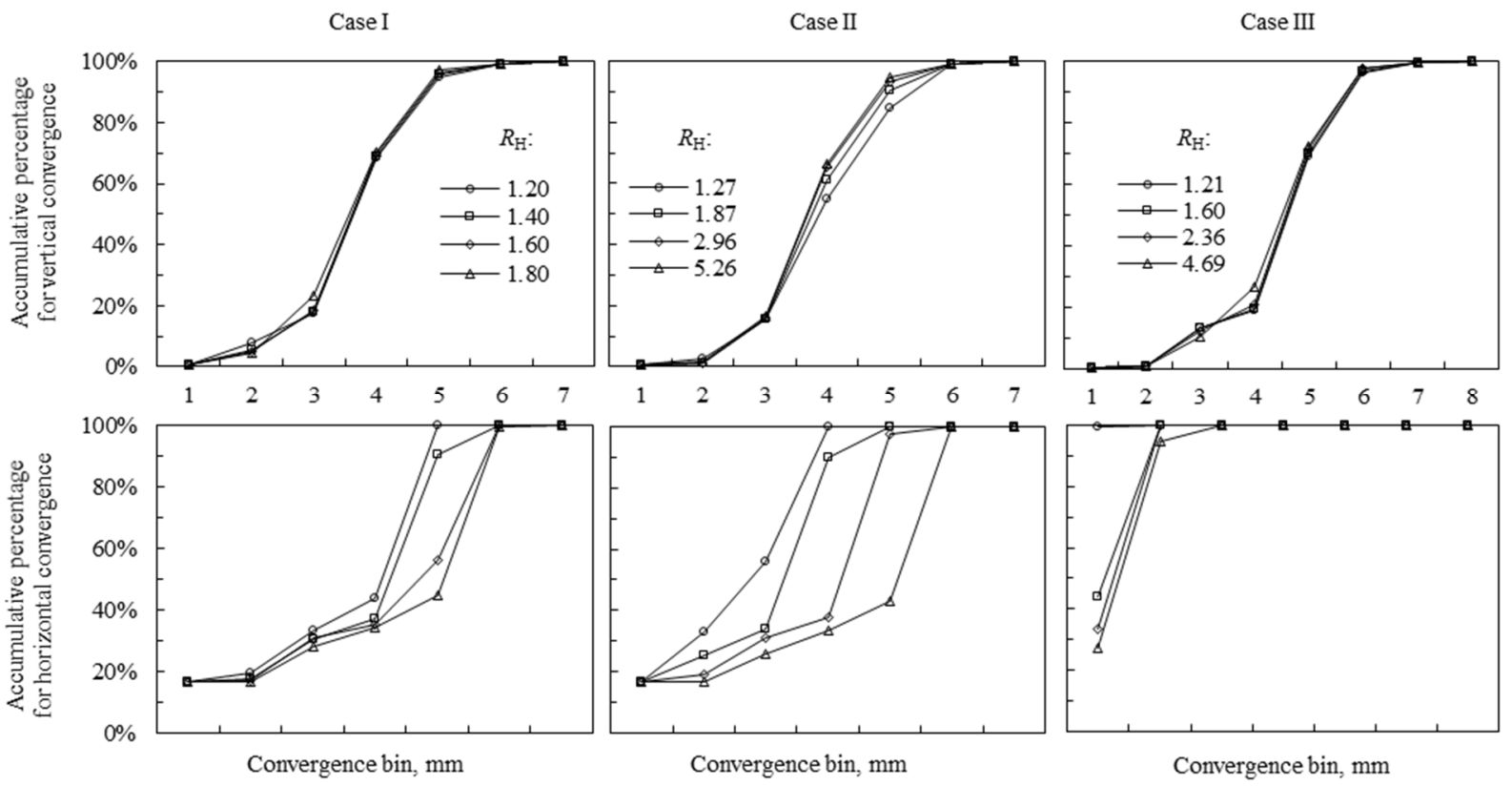

Fig. 3.7 Accumulated percentage curves of roadway convergences at different in situ stress conditions.

increasing impact on the maximum horizontal convergence for all roadways. Ventilation channels have minor horizontal convergence, mainly because their axes are mostly parallel to the maximum horizontal stress. With the decrease of the mean stress $M$, i.e. with vertical stress transferred from minimum principal stress to intermediate to maximum principal stress, such influences of $R_{\mathrm{H}}$ on both the vertical and horizontal convergence becomes minor. In addition, as the mean stress $M$ falls, the general magnitude of the roadway maximum vertical convergence rises while the maximum horizontal convergence drops. Furthermore, the influences of both $R_{\mathrm{H}}$ and $M$ on the horizontal convergence are more significant than those on the vertical convergence.

(2) The influence of $R_{\mathrm{H}}$ on the cumulative distribution of roadway convergence

The convergence data of all the roadways calculated based on the measurement points on the roadway surface were then statistically analysed for 

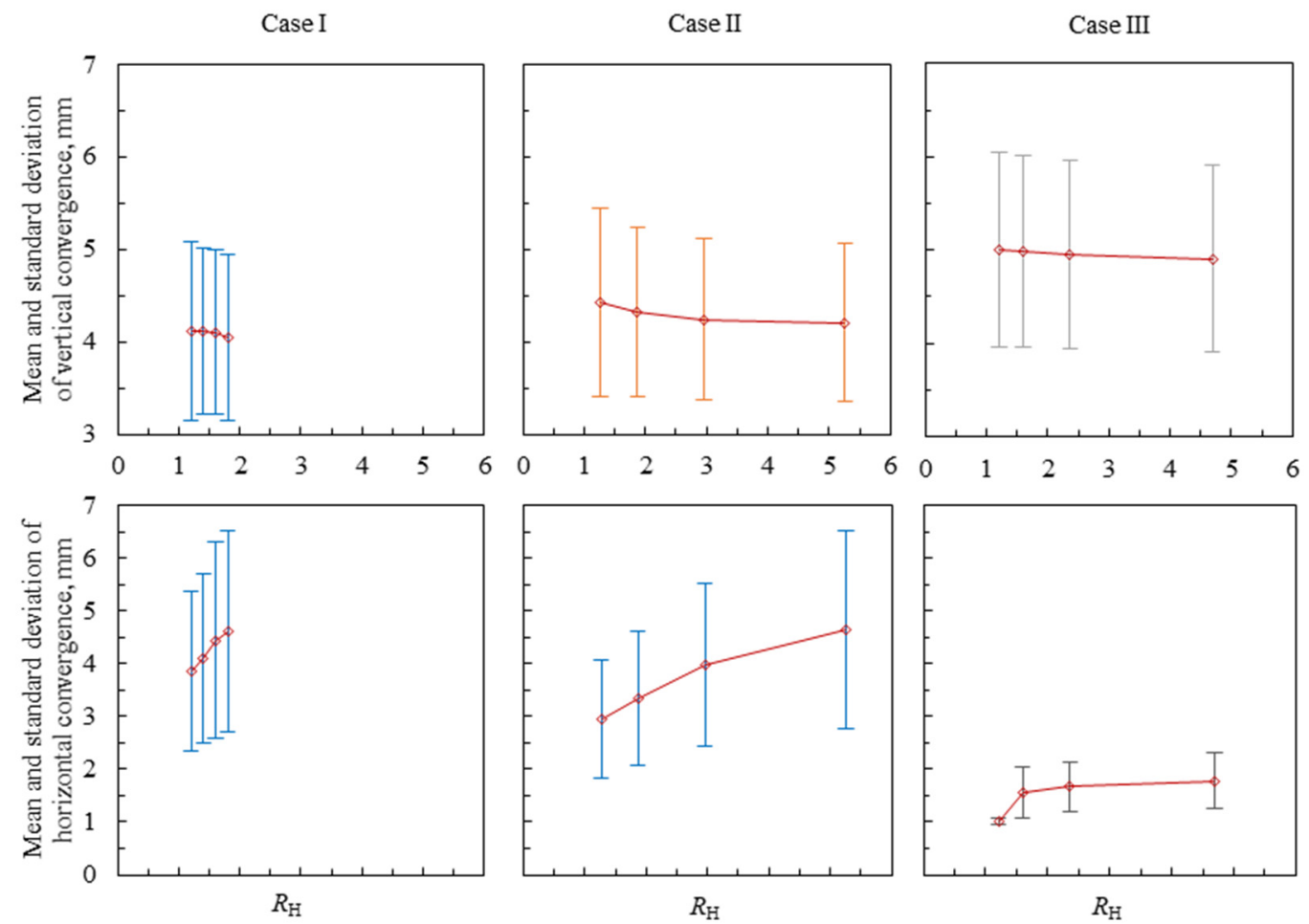

Fig. 3.8 Mean and standard deviation of the convergence data at different in situ stress conditions.

each in situ stress condition. The cumulative distributions of the roadway convergence were plotted against a series of convergence bin, as shown in Figure 3.7. Generally for each case, the horizontal convergence curve drops with the increase of $R_{\mathrm{H}}$, and the curves have larger variation when $R_{\mathrm{H}}$ changes within a broader range. That is to say, the stronger anisotropic stress field causes higher accumulative percentages for larger horizontal convergence magnitude, increasing the overall roadway deformation. On the other hand, the cumulative distribution of vertical convergence varies insignificantly at the change of $R_{\mathrm{H}}$, mainly because both the mean stress and the vertical stress remain constant at the same case, while the horizontal stress ratios and magnitudes change considerably.

Both the mean and standard deviation of the convergence data were further analysed, as plotted in Figure 3.8. It can be seen that with the increase of $R_{\mathrm{H}}$, both mean and standard deviation of vertical convergence data decreased, while those of horizontal convergence data increased, since most parts of the excavations are nearly perpendicular to the orientation of $\sigma_{\mathrm{H}}$. The changing rate of horizontal convergence mean and standard deviation is much larger than vertical convergence at the same modelling case, as the vertical stress remains constant during the change of $R_{\mathrm{H}}$. With the decrease of the mean stress $M$, the vertical convergence increased while horizontal convergence decreased, as the magnitude ranges of $\sigma_{\mathrm{H}}$ also declined. At lower levels of the mean stress $M$, the curve slope decreased, or rather the influence of $R_{\mathrm{H}}$ reduced.

\subsubsection{STRENGTH-STRESS RATIO}

Both the cumulative distribution curves and the normal density distributions of the strength-stress ratio measured along the roadways were plotted in Figure 3.9. With the increase of the principal stress ratio $R_{\mathrm{H}}$, the cumulative distribution curve is higher while both the mean and the variance of the strengthstress ratio decreased in all three cases, meaning that the overall safety and stability of the roadways decreased.

An empirical stability model was also proposed to describe the cumulative distribution curves of the roadway strength-stress ratio:

$P=\left[\left(a_{\mathrm{s}} \cdot R_{s}\right)^{\wedge}(1 /(1-b))+1\right]^{\wedge}(-b)$

where, $P$ is accumulative percentage of the strengthstress ratio $R_{s}$, and $a_{\mathrm{s}}$ and $b$ are fitting parameters. $a_{\mathrm{s}}$ is a stability parameter related to the horizontal stress ratio $R_{\mathrm{H}}$ and the mean stress $M$.

$a_{\mathrm{s}}=\alpha R_{\mathrm{H}}+\beta M+\gamma$

where, $\alpha, \beta$, and $\gamma$ are fitting parameters, and $M$ is mean in situ stress.

Given that a small number of samples were used to fit the cumulative distribution curves, the generalised instead of ordinary least squares method was used to recover the full uncertainty, considering the effect of covariance matrix. Predicted curves according to Equation (3.8) are shown in Figure 3.9 together with the values of fitting parameters as well as the original statistical data $\left(R^{2}=0.96\right)$. This is very interesting, as the overall stability of the excavations 

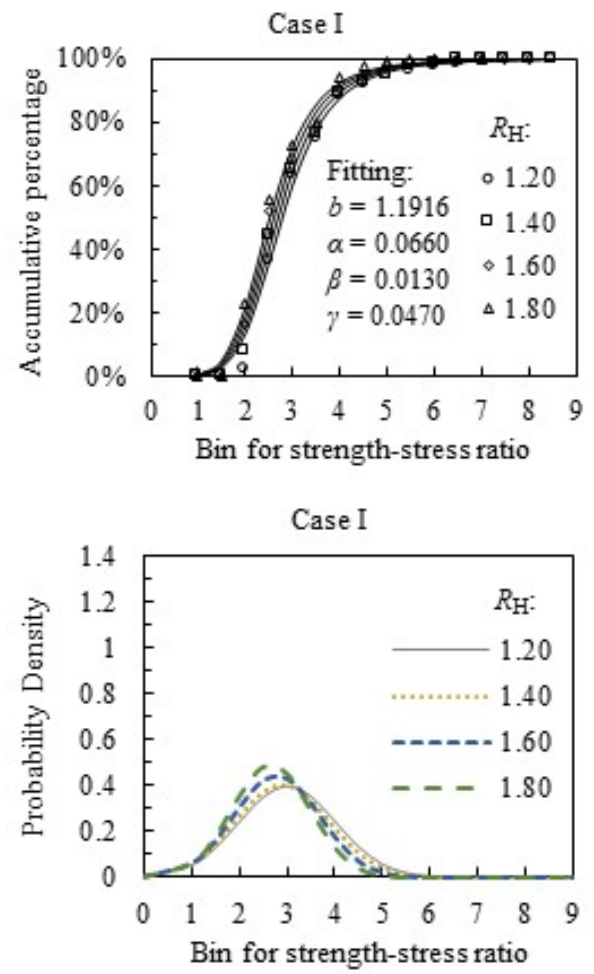

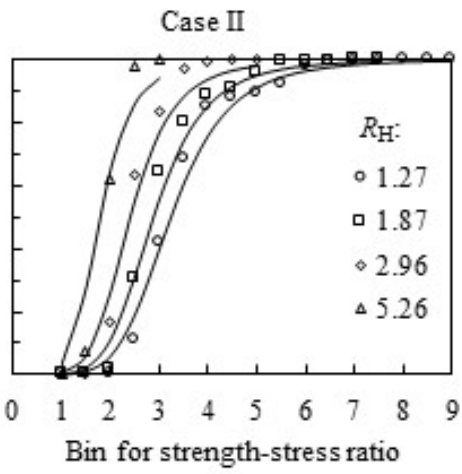

Case II

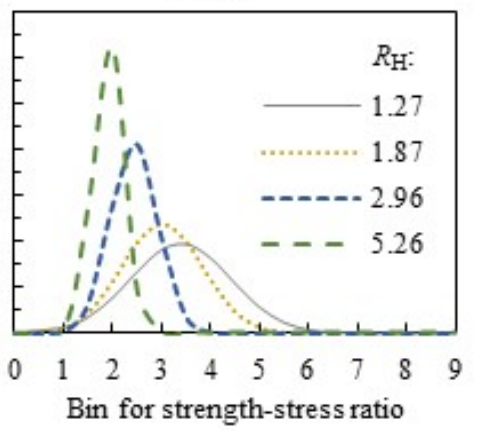

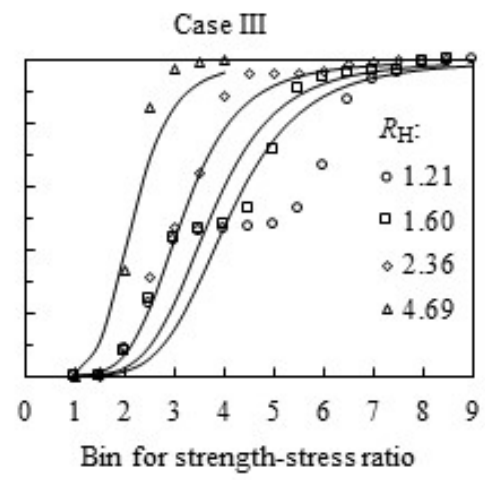

Case III

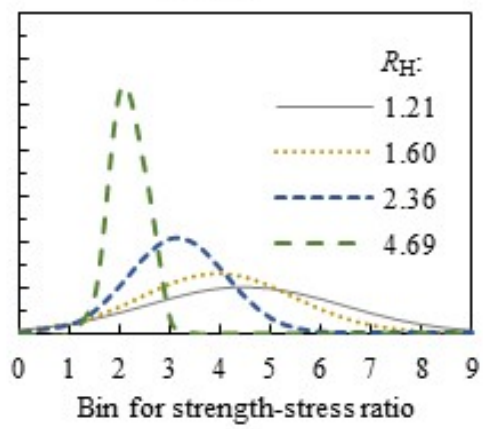

Fig. 3.9 Accumulated percentage and probability density curves of strength-stress ratio at different in situ stress conditions.

with complicated configurations can thus be quantitatively evaluated. The mean stress and the horizontal stress ratio are mainly focused on as two of the most important parameters controlling the URF stability. The stability parameter $a_{\mathrm{s}}$ mathematically combines these two parameters, while representing a clear physical meaning i.e. the overall stability or the potential of failure. The smallest value of $a_{\mathrm{s}}$ in all twelve modelling conditions represents the most favourable case (scenario III, subcase \#4) among the listed in situ stress scenarios in Table 2.7. As in most cases underground excavations have complicated geometry layout and configuration, one single value e.g. the peak convergence or minimum strength-stress ratio cannot accurately describe the worst condition. The proposed stability model provides a better but simple mathematical method to comprehensively evaluate the situation, and offers a reference point for stability analysis and layout planning optimisation in similar conditions.

\section{SUMMARY AND CONCLUSIONS}

This paper studied the influence of different preexcavation in situ state of stress on the deformation and strength-stress ratio of the planned Bukov URF Phase II in Czech Republic using the numerical software FLAC3D. The Hoek-Brown criterion was adopted to simulate the constitutive behaviour of the rock mass. Corresponding geomechanical properties of the rock mass was estimated by combining field geological mapping, laboratory experiments and theoretical calculation. The most probable conditions of the in situ stress were derived by back calculation from the normal distributions of the mean principal stress and principal stress ratios instead of a direct average of the in situ stress components. The model was run on three scenarios and totally twelve subcases. Both the displacement/convergence and the strengthstress ratio of the URF excavation were focused on for the sensitivity and stability analysis. Modelling results show that both the in situ stress state and excavation/layout-induced stress redistribution jointly influence the deformation and stability of the URF. The significance and necessity of careful treatment of the in situ stress data in numerical modelling was highlighted. Important conclusions are drawn as follows:

(1) The influence of the horizontal stress ratio $R_{\mathrm{H}}$ and the mean stress $M$ on the stability of the Bukov URF Phase II was analysed from several different perspectives, including the global model parameters i.e. the minimum strength-stress ratio (MSR) and the maximum displacement magnitude (MD), the individual roadway parameters i.e. the maximum horizontal and vertical convergence, and the cumulative distribution curves of both the convergences and the strength-stress ratio collected along all the roadways. Results indicated that the increased horizontal stress anisotropy and the mean stress level jointly increase the overall deformation and lower the URF safety and stability condition. Such influences on the horizontal convergence are more considerable than those on the vertical convergence. 
(2) A novel empirical stability model was proposed to describe the cumulative distribution of the strength-stress ratio along all the roadways with complex layout, and takes into account both $R_{\mathrm{H}}$ and $M$. The stability parameter $a_{\mathrm{s}}$ in the model is defined to have clear physical meaning, which quantitatively describes the overall stability of the URF with complicated configuration.

Future detailed geotechnical monitoring during and after the excavation of Bukov URF Phase II is essential to validate the adopted Hoek-Brown model where some assumptions are made e.g. the ignorance of the intermediate principal stress and rock anisotropy, and to refine the numerical modelling and contribute to the design and construction of the next- stage national nuclear waste repository in Czech Republic. In addition, the proposed stability model needs further validation in similar tunneling and underground excavation projects to verify its mathematical ubiquity.

\section{ACKNOWLEDGEMENT}

This work was supported by the Czech Radioactive Waste Repository Authority [grant number 4.1.5.1/ESS:SURAO-2014-2304] and the Czech Academy of Sciences [grant number RVO: 68145535]. The authors thank the Czech Radioactive Waste Repository Authority for permission to publish this work. The first author was supported by the Program to support prospective human resources post Ph.D. candidates in the Czech Academy of Sciences.

\section{REFERENCES}

Abdellah, W.R., Ali, M.A. and Yang, H.S.: 2018, Studying the effect of some parameters on the stability of shallow tunnels. J. Sustain. Min., 17, 1, 20-33. DOI: $10.1016 /$ j.jsm.2018.02.001

Amadei, B. and Stephansson, O.: 1997, Rock stress and its measurement. Springer, Dordrecht, 23-120. DOI: $10.1007 / 978-94-011-5346-1$

Anderson, E.M.: 1905, The dynamics of faulting. Trans. Ed. Geol. Soc., 8, 387-402. DOI: 10.1144/transed.8.3.387

Apted, M.: 2019, Underground research laboratories: purposes, evolution of objectives, and brief history. U.S. Nuclear Waste Technical Review Board. https://www.nwtrb.gov/docs/defaultsource/meetings/2019/april/apted.pdf?sfvrsn $=6$.

Apted, M.J. and Ahn, J.: 2017, Geological repository systems for safe disposal of spent nuclear fuels and radioactive waste (2nd ed.). Woodhead Publishing, Sawston Cambridge, 3-26. DOI: 10.1016/B978-0-08-100642-9.12001-8

Barton, N., Lien, R. and Lunde, J.: 1974, Engineering classification of rock masses for the design of tunnel support. Rock Mech. Rock Eng., 6, 4, 189-236. DOI: 10.1007/BF01239496

Bieniawski, Z.T.: 1989, Engineering rock mass classifications: a complete manual for engineers and geologists in mining, civil, and petroleum engineering. John Wiley \& Sons, New York, 54-58.
Brady, B.H.G. and Brown, E.T.: 2007, Pre-mining state of stress. In: Rock Mechanics for underground mining (3rd ed.). Springer, Dordrecht, 142-164. DOI: $10.1007 / 978-1-4020-2116-95$

Brown, E.T. and Hoek, E.: 1978, Trends in relationships between measured in-situ stresses and depth. Int. J. Rock Mech. Min. Sci. Geomech. Abstr., 15, 4, $211-$ 215. DOI: 10.1016/0148-9062(78)91227-5

Bukovská, Z. at al.: 2020, Data acquisition from the deep horizons of the Rožná Mine. RAWRA Technical Report (No. 464/2020/ENG). Czech Radioactive Waste Repository Authority, Prague, $48 \mathrm{pp}$.

Bukovská, Z., Soejono, I., Vondrovic, L., Vavro, M., Souček, K., Buriánek, D., Dobeš, P., Švagera, O., Waclawik, P. and Řihošek, J.: 2019, Characterization and $3 \mathrm{D}$ visualization of underground research facility for deep geological repository experiments: A case study of underground research facility Bukov, Czech Republic. Eng. Geol., 259, 105186. DOI: $10.1016 /$ j.enggeo.2019.105186

Corkum, A.G., Damjanac, B. and Lam, T.: 2018, Variation of horizontal in situ stress with depth for long-term performance evaluation of the Deep Geological Repository project access shaft. Int. J. Rock Mech. Min. Sci., 107, 75-85. DOI: 10.1016/j.ijrmms.2018.04.035

Delay, J., Bossart, P., Ling, L.X., Blechschmidt, I., Ohlsson, M., Vinsot, A., Nussbaum, C. and Maes, N.: 2014, Three decades of underground research laboratories: what have we learned? Geol. Soc. London Spec. Publ., 400, 1, 7-32. DOI: 10.1144/SP400.1

Feiveson, H., Mian, Z., Ramana, M.V and von Hippel, F.: 2011, Managing nuclear spent fuel: Policy lessons from a 10-country study. Bull. At. Sci. https://thebulletin.org/2011/06/managing-nuclearspent-fuel-policy-lessons-from-a-10-country-study.

Haimson, B.C. and Cornet, F.H.: 2003, ISRM suggested methods for rock stress estimation-part 3: hydraulic fracturing (HF) and/or hydraulic testing of preexisting fractures (HTPF). Int. J. Rock Mech. Min. Sci., 40, 7-8, 1011-1020. DOI: 10.1016/j.ijrmms.2003.08.002

Heidarzadeh, S., Saeidi, A. and Rouleau, A.: 2021, The damage-failure criteria for numerical stability analysis of underground excavations: A review. Tunn. Underg. Space Technol., 107, 103633. DOI: $10.1016 / j$.tust.2020.103633

Herget, G.: 1974, Ground stress determinations in Canada. Rock Mechanics, 6, 1, 53-64. DOI: $10.1007 / \mathrm{BF} 01238053$

Hoek, E., Carter, T.G. and Diederichs, M.S.: 2013, Quantification of the geological strength index chart. In: Pyrak-Nolte, Chan, A., Dershowitz, W., Morris, J. and Rostami J. (Eds.): 47th US Rock Mechanics/Geomechanics Symposium, San Francisco, CA, 1757-1764.

Hudson, J.A., Cornet, F.H. and Christiansson, R.: 2003, ISRM Suggested methods for rock stress estimationPart 1: Strategy for rock stress estimation. Int. J. Rock Mech. Min. Sci., 40, 7-8, 991-998. DOI: $10.1016 /$ j.ijrmms.2003.07.011

Itasca Consulting Group: 2012, FLAC3D 5.0 manual. Itasca Consulting Group, Minneapolis.

Kř́bek, B. and Hájek, A.: 2005, Rožná uranium deposit: model of late Variscan and post Variscan 
mineralizations. Czech Geological Survey, Prague, 15 pp., (in Czech).

Laverov, N.P., Yudintsev, S.V, Kochkin, B.T. and Malkovsky, V.I.: 2016, The Russian strategy of using crystalline rock as a repository for nuclear waste. Elements, 12, 4, 253-256.

DOI: 10.2113/gselements.12.4.253

Martin, C.D.: 2007, Quantifying in situ stress magnitudes and orientations for Forsmark. Forsmark stage 2.2. SKB Report (No. R-07-26), Swedish Nuclear Fuel and Waste Management Co., Stockholm, 71-80.

Napa-García, G.F., Câmara, T.R. and Torres, V.F.N.: 2019, Optimization of room-and-pillar dimensions using automated numerical models. Int. J. Min. Sci. Technol., 29, 5, 797-801.

DOI: $10.1016 /$ j.ijmst.2019.02.003

NEA-OECD: 2013, Underground reserch laboratories (URL) (NEA Report No. 78122). https://www.oecd-nea.org/rwm/reports/2013/78122rwm-url-brochure.pdf.

Patocka, M. and Jaros, M.: 2020, Geological and geotechnical condition of URF Bukov roadways drivage - Stage II. DIAMO Technical Report, DIAMO, s.p., 98 pp., (in Czech).

Peng, S.S., Cheng, J., Du, F. and Xue, Y.: 2019, Underground ground control monitoring and interpretation, and numerical modeling, and shield capacity design. Int. J. Min. Sci. Technol., 29, 1, 7985. DOI: 10.1016/j.ijmst.2018.11.026

Ptáček, J., Melichar, R., Hájek, A., Koníček, P., Souček, K., Staš, L., Kříž, P. and Lazárek, J.: 2013, Structural analysis within the Rožná and Olší uranium deposits (Strážek Moldanubicum) for the estimation of deformation and stress conditions of underground gas storage. Acta Geodyn. Geomater., 10, 2, 237-246. DOI: 10.13168/AGG.2013.0024

Renani, H.R. and Martin, C.D.: 2020, Factor of safety of strain-softening slopes. J. Rock Mech. Geotech. Eng., 12, 3, 473-483. DOI: 10.1016/j.jrmge.2019.11.004

Rocscience Inc.: 2017, RocData (5.0). https://www.rocscience.com/help/rocdata.

Saeidi, A., Heidarzadeh, S., Lalancette, S. and Rouleau, A.: 2021, The effects of in situ stress uncertainties on the assessment of open stope stability: Case study at the Niobec Mine, Quebec (Canada). Geomech. Energy Environ., 25, 100194. DOI: $10.1016 /$ j.gete.2020.100194

Sainsbury, B.L. and Sainsbury, D.P.: 2017, Practical use of the ubiquitous-joint constitutive model for the simulation of anisotropic rock masses. Rock Mech. Rock Eng., 50, 1507-1528. DOI: $10.1007 / \mathrm{s} 00603-017-1177-3$
Singh, B. and Goel, R.K.: 2011, In situ stresses. In: Singh, B. and Goel, R.K. (Eds.): Engineering Rock Mass Classification. Butterworth-Heinemann, Oxford, 345350. DOI: 10.1016/B978-0-12-385878-8.00028-8

Sjöberg, J., Christiansson, R. and Hudson, J.A.: 2003, ISRM suggested methods for rock stress estimation: Part 2: overcoring methods. Int. J. Rock Mech. Min. Sci., 40, 7-8, 999-1010. DOI: 10.1016/j.ijrmms.2003.07.012

Souček, K., Vavro, M., Staš, L., Kaláb, Z., Koníček, P., Georgiovská, L., Kaláb, T., Konečný, P., Kolcun, A., Králová, L., Kubina, L., Lednická, M., Malík, J., Martinec, P., Ptáček, J., Vavro, L., Waclawik, P. and Zajícová, V.: 2018, Complex geological characterization of URF Bukov - part I - Geotechnical characterization. RAWRA Technical Report (No. 221/2018), Czech Radioactive Waste Repository Authority, Prague, 345 pp., (in Czech).

Souček, K., Vavro, M., Staš, L., Vavro, L., Waclawik, P., Koniček, P., Ptáček, J. and Vondrovic, L.: 2017, Geotechnical characterization of Bukov underground research facility. Procedia Eng., 191, 711-718. DOI: 10.1016/j.proeng.2017.05.236

Stephansson, O. and Zang, A.: 2012, ISRM suggested methods for rock stress estimation-part 5: establishing a model for the in situ stress at a given site. Rock Mech. Rock Eng., 45, 6, 955-969. DOI: $10.1007 / \mathrm{s} 00603-012-0270-\mathrm{x}$

Vavro, M., Souček, K., Staš, L., Waclawik, P., Vavro, L., Koniček, P. and Ptáček, J.: 2015, Application of alternative methods for determination of rock quality designation (RQD) index: a case study from the Rožná I uranium mine, Strážek Moldanubicum, Bohemian Massif, Czech Republic. Can. Geotech. J., 52, 10, 1466-1476. DOI: 10.1139/cgj-2014-0377

Wang, J., Chen, L., Su, R. and Zhao, X.: 2018, The Beishan underground research laboratory for geological disposal of high-level radioactive waste in China: planning, site selection, site characterization and in situ tests. J. Rock Mech. Geotech. Eng., 10, 3, 411435. DOI: 10.1016/j.jrmge.2018.03.002

Zang, A. and Stephansson, O.: 2010, Stress field of the Earth's crust. Springer, Dordrecht, 225-252. DOI: $10.1007 / 978-1-4020-8444-7$

Zhang, Y. and Mitri, H.S.: 2008, Elastoplastic stability analysis of mine haulage drift in the vicinity of mined stopes. Int. J. Rock Mech. Min. Sci., 45, 4, 574-593. DOI: 10.1016/j.ijrmms.2007.07.020 